\title{
Can Cap-Assisted Colonoscopy Be a Savior for Right Side Interval Cancer?
}

\author{
Hyung Hun Kim
}

Published online: 21 October 2012

(c) Springer Science+Business Media New York 2012

There is no doubt that effective colorectal cancer screening relies on early identification and removal of polyps with neoplastic potential [1,2]. Although colonoscopy is regarded as the best method for detecting colonic neoplasm, it does have limitations. Right-sided lesions, flat polyps, and variable detection of endoscopist adenoma are all reasons why polyps are missed and interval cancers develop after a negative screening colonoscopy. Successful colorectal cancer protection by colonoscopy depends on complete intubation of the colon combined with careful and complete visualization of the colonic mucosal surface on withdrawal. A large populationbased study showed that failure to intubate the cecum is not uncommon, especially for less experienced endoscopists; it was estimated to occur in $13.1 \%$ of attempted colonoscopies [3]. Furthermore, occurrence of missed adenoma ranging from 13 to $26 \%$ has been reported [4]. Adenoma detection has been shown to be an independent predictor of the risk of interval colorectal cancer after screening colonoscopy [5]. Several types of new technology have therefore been developed to improve adenoma detection, including high-definition white-light colonoscopy, pan-chromoendoscopy, wide-angle colonoscopy, virtual chromoendoscopy, third-eye retroscopy (TER), and cap-assisted colonoscopy (CAC) [6] .

CAC is a simple method in which a transparent or nontransparent rubber cap is attached to the tip of a colonoscope with an appropriate protrusion length. The cap can be readily equipped and the field of vision is not substantially affected by the cap. Although conflicting results have been reported after recent studies that compared CAC with standard colonoscopy (SC), CAC has been

H. H. Kim $(\bowtie)$

Department of Internal Medicine, Kosin University College of Medicine, 34 Amnam-dong, Seo-gu, Busan 602-702, Korea e-mail:drhhkim@gmail.com reported to be associated with improved polyp detection, reduced cecal intubation time, and enhanced cecal intubation [7-10].

Theoretically, CAC can detect polyps better than SC, especially those behind semilunar folds. CAC can help depress semilunar folds, thereby reducing the blind mucosal surface area, and may improve the efficiency of adenoma detection [6]. A study of lesions missed at colonoscopy but detected by computed tomography colonography revealed that $67 \%$ lie on the proximal side of semilunar folds [11]. The cap also keeps the tip of the endoscope a distance from the colonic mucosa, particularly around colonic bends, and provides a continuous visual field of the lumen direction. CAC seeks to reduce the percentage of the colonic mucosal surface that is left unexamined in a "complete" colonoscopy [12]. Largescale meta-analyses have revealed that CAC improves the detection of colonic neoplasm compared with standard colonoscopy (SC) both in terms of the number of patients identified with at least one polyp and in terms of the polyp miss rate determined by tandem colonoscopy $[6,13]$. It seems that CAC predominantly improves the detection of small $(6-9 \mathrm{~mm})$ and diminutive $(5 \mathrm{~mm})$ adenomas. A study of colonoscopic miss rates determined by back-toback colonoscopies revealed the miss rate was $13 \%$ for small adenomas and $27 \%$ for diminutive adenomas [4]. Because up to $15.5 \%$ of small adenomas and up to $3.4 \%$ of diminutive adenomas contain high-grade dysplasia, it is possible that those that are missed contribute to the occurrence of interval cancers $[14,15]$. In a Japanese study, adenoma detection, particularly of sessile and small adenomas, was higher in the retractable cap group than the non-cap group (29 vs. $24 \%$ ) [16]. Investigation using a colonic training model revealed that visualization of the colonic surface was significantly increased during CAC 
compared with SC, and that the improvement in visualization was only significant for the right colon, but not for the rectum, sigmoid, or descending colon [17]. Evidence supporting the efficacy of CAC for identifying colonic neoplastic lesions is accumulating continuously. The advantages of CAC in the detection of small and diminutive adenomas, particularly sessile-type right side lesions, may reduce the incidence of interval cancer.

CAC seems to facilitate cecal intubation and reduce intubation time. Two meta-analyses have shown that a higher cecal intubation rate can be achieved with CAC than SC [13, 18]. It has been speculated that less-experienced operators would obtain greater benefit from such a device [10]. Expert endoscopists have been shown to have a shorter cecal intubation time with CAC than SC [6]. A randomized controlled trial reported that the successful intubation rate for $\mathrm{CAC}$ was 67 versus $21 \%$ for SC in failed colonoscopy [19]. Furthermore, $\mathrm{CAC}$ has been reported to reduce cecal intubation time in difficult cases, for example old age, before abdominal operation, and poor bowel preparation [20]. CAC may have a role in improving cecal intubation in a difficult or failed colonoscopy. A recent study revealed that the limited use of low-air insufflation in the rectum and sigmoid colon shortened cecal intubation time and reduced post-procedural abdominal bloating [21]. With the cap, easier anticipation of the direction in which the colonoscope should be advanced, with less air insufflation, potentially enables more comfortable examination. The combination of these two characteristics of CAC, namely a higher cecal intubation rate and a higher rate of detection of neoplastic lesions, indicates that $\mathrm{CAC}$ is superior to $\mathrm{SC}$ as a screening tool for detection of colorectal neoplasms, especially right side lesions.

In this issue of Digestive Diseases and Sciences, Horiuchi et al. [22] reconfirm the efficacy of CAC in detecting neoplastic lesions compared with SC. These authors investigated 2,301 colonoscopies-1,165 CACs and 1,136 SCs-performed by four endoscopists. The authors estimated that the mean number of adenomas per subject in the control group would be 0.3 (i.e., $30 \%$ detection). For a $30 \%$ increase in adenoma detection with CAC, a total of at least 1,000 subjects were required in each group. There was no specific preference for CAC or SC, and there was no bias in the percentage of CAC cases performed by the four endoscopists $(51,49,51,51 \%, p=0.93)$. Overall, the total number of adenomas detected with CAC was significantly higher than with SC (586 vs. 484, $p<0.0001$ ). Importantly, CAC significantly increased adenoma detection in the right colon compared with the left colon (19 vs. $12 \%, p=0.0001$ ). This confirms the previous finding in a colonic training model that CAC significantly improves

Table 1 Randomized controlled trials comparing cap-assisted colonoscopy with standard colonoscopy

\begin{tabular}{|c|c|c|c|c|c|c|c|}
\hline \multirow[t]{2}{*}{ Study } & \multicolumn{2}{|c|}{ Sample size } & \multirow[t]{2}{*}{ Cap length } & \multirow{2}{*}{$\begin{array}{l}\text { Lesion } \\
\text { detection }\end{array}$} & \multirow{2}{*}{$\begin{array}{l}\text { Cecal intubation } \\
\text { rate }\end{array}$} & \multirow{2}{*}{$\begin{array}{l}\text { Cecal intubation } \\
\text { time }\end{array}$} & \multirow{2}{*}{ Comfort } \\
\hline & $\mathrm{CAC}$ & Control & & & & & \\
\hline Harada et al. [24] & 289 & 303 & $2 \mathrm{~mm}$ & $\mathrm{CAC}=\mathrm{SC}$ & $\mathrm{CAC}=\mathrm{SC}$ & $\mathrm{CAC}>\mathrm{SC}$ & $\mathrm{CAC}>\mathrm{SC}$ \\
\hline Kondo et al. [10] & 221 & 235 & 2 or $4 \mathrm{~mm}$ & $\mathrm{CAC}>\mathrm{SC}$ & $\mathrm{CAC}=\mathrm{SC}$ & $\mathrm{CAC}>\mathrm{SC}$ & NS \\
\hline Rastogi et al. [25] & 210 & 210 & $4 \mathrm{~mm}$ & $\mathrm{CAC}>\mathrm{SC}$ & $\mathrm{CAC}=\mathrm{SC}$ & $\mathrm{CAC}>\mathrm{SC}$ & NI \\
\hline Shida et al. [26] & 174 & 198 & $4 \mathrm{~mm}$ & NI & $\mathrm{CAC}=\mathrm{SC}$ & $\mathrm{CAC}>\mathrm{SC}$ & $\mathrm{CAC}>\mathrm{SC}$ \\
\hline Tee et al. [27] & 200 & 200 & $4 \mathrm{~mm}$ & $\mathrm{CAC}=\mathrm{SC}$ & $\mathrm{CAC}=\mathrm{SC}$ & $\mathrm{CAC}=\mathrm{SC}$ & $\mathrm{NI}$ \\
\hline $\begin{array}{l}\text { de Wijkerslooth et al. } \\
{[28]}\end{array}$ & 656 & 683 & $4 \mathrm{~mm}$ & $\mathrm{CAC}=\mathrm{SC}$ & $\mathrm{CAC}=\mathrm{SC}$ & $\mathrm{CAC}>\mathrm{SC}$ & $\mathrm{CAC}>\mathrm{SC}$ \\
\hline Dai et al. [29] & 121 & 129 & $4 \mathrm{~mm}$ & $\mathrm{CAC}=\mathrm{SC}$ & $\mathrm{CAC}=\mathrm{SC}$ & $\begin{array}{r}\mathrm{CAC}>\mathrm{SC} \text { for } \\
\text { inexperienced }\end{array}$ & $\mathrm{CAC}>\mathrm{SC}$ \\
\hline Choi et al. [30] & 114 & 114 & $4 \mathrm{~mm}$ & $\mathrm{CAC}=\mathrm{SC}$ & $\mathrm{CAC}=\mathrm{SC}$ & $\mathrm{CAC}>\mathrm{SC}$ & $\mathrm{CAC}=\mathrm{SC}$ \\
\hline Horiuchi et al. [16] & 424 & 411 & $\begin{array}{l}7 \mathrm{~mm} \\
\text { retractable }\end{array}$ & $\mathrm{CAC}>\mathrm{SC}$ & $\mathrm{CAC}=\mathrm{SC}$ & $\mathrm{CAC}=\mathrm{SC}$ & NI \\
\hline Kim et al. [20] & 150 & 145 & $10 \mathrm{~mm}$ & $\mathrm{CAC}>\mathrm{SC}$ & $\mathrm{CAC}=\mathrm{SC}$ & $\begin{array}{l}\mathrm{CAC}>\mathrm{SC} \text { in difficult } \\
\text { cases }\end{array}$ & $\mathrm{CAC}=\mathrm{SC}$ \\
\hline Tada et al. [7] & 70 & 70 & $10 \mathrm{~mm}$ & $\mathrm{CAC}>\mathrm{SC}$ & NI & $\mathrm{CAC}=\mathrm{SC}$ & $\mathrm{CAC}=\mathrm{SC}$ \\
\hline Lee et al. [19] & 499 & 501 & NS & $\mathrm{CAC}<\mathrm{SC}$ & $\begin{array}{l}\mathrm{CAC}>\mathrm{SC} \text { in failed } \\
\text { cases }\end{array}$ & $\mathrm{CAC}>\mathrm{SC}$ & NI \\
\hline
\end{tabular}

CAC, cap-assisted colonoscopy; SC, standard colonoscopy; NS, not stated; NI, not investigated

$\mathrm{CAC}>\mathrm{SC}$ means CAC was superior to SC: more lesions detected, higher cecal intubation rate, and more comfortable during colonoscopy compared with SC

$\mathrm{CAC}=\mathrm{SC}$ means no difference between $\mathrm{CAC}$ and $\mathrm{SC}$ for the data measured

$\mathrm{CAC}<\mathrm{SC}$ means CAC was inferior to SC: fewer lesions detected, lower cecal intubation rate, and more abdominal discomfort during colonoscopy compared with SC 
visualization of the right colon [17]; this improved detection of right side neoplastic lesions by CAC could reduce the incidence of interval cancer. Cecal intubation rate and cecal intubation time were similar for CAC and SC in this study. This might have been because of the short length of the cap used $(4 \mathrm{~mm})$. According to one meta-analysis, the length of cap used can affect the rate of polyp detection. Shorter caps are better for polyp detection ( 2 or $4 \mathrm{~mm}$ ), whereas longer caps $(7-11 \mathrm{~mm})$ are associated with faster cecal intubation [6].

Several future modalities have been designed to increase the colonic mucosal surface area exposed to the visual field; high-definition white light colonoscopy, pan-chromoendoscopy, wide-angle colonoscopy, colonoscopy in retroversion, virtual chromoendoscopy, and TER, but most of these techniques are associated with increased procedure duration, higher cost, and reduced patient acceptance. A recent multicenter trial found that TER significantly increased adenoma detection in comparison with SC [23]; the problem with this modality would be its additional cost. CAC is more practical and less expensive than TER, but TER and CAC have not yet been compared. Interestingly, no study has reported CAC with a 5-6 mm length cap. Because shorter caps may improve polyp detection and longer caps reduce cecal intubation time, medium length caps (5-6 mm) may have both advantages. Use of a cap in screening colonoscopy in this era of right side colon lesions and interval cancer is likely to increase continuously given the several advantages of CAC discussed above (Table 1).

\section{References}

1. Winawer SJ, Zauber AG, Fletcher RH, et al. Guidelines for colonoscopy surveillance after polypectomy: a consensus update by the US multi-society task force on colorectal cancer and the American cancer society. Gastroenterology. 2006;130:1872-1885.

2. Pignone M, Rich M, Teutsch SM, Berg AO, Lohr KN. Screening for colorectal cancer in adults at average risk: a summary of the evidence for the U.S. preventive services task force. Ann Intern Med. 2002;137:132-141.

3. Shah HA, Paszat LF, Saskin R, Stukel TA, Rabeneck L. Factors associated with incomplete colonoscopy: a population-based study. Gastroenterology. 2007;132:2297-2303.

4. Rex DK, Cutler CS, Lemmel GT, et al. Colonoscopic miss rates of adenomas determined by back-to-back colonoscopies. Gastroenterology. 1997;112:24-28.

5. Kaminski MF, Regula J, Kraszewska E, et al. Quality indicators for colonoscopy and the risk of interval cancer. $N$ Engl J Med. 2010;362:1795-1803.

6. Ng SC, Tsoi KK, Hirai HW, et al. The efficacy of cap-assisted colonoscopy in polyp detection and cecal intubation: a metaanalysis of randomized controlled trials. Am J Gastroenterol. 2012;107:1165-1173.

7. Tada M, Inoue H, Yabata E, Okabe S, Endo M. Feasibility of the transparent cap-fitted colonoscope for screening and mucosal resection. Dis Colon Rectum. 1997;40:618-621.
8. Dafnis GM. Technical considerations and patient comfort in total colonoscopy with and without a transparent cap: initial experiences from a pilot study. Endoscopy. 2000;32:381-384.

9. Matsushita M, Hajiro K, Okazaki K, Takakuwa H, Tominaga M. Efficacy of total colonoscopy with a transparent cap in comparison with colonoscopy without the cap. Endoscopy. 1998;30:444-447.

10. Kondo S, Yamaji Y, Watabe $\mathrm{H}$, et al. A randomized controlled trial evaluating the usefulness of a transparent hood attached to the tip of the colonoscope. Am J Gastroenterol. 2007;102:75-81.

11. Pickhardt PJ, Nugent PA, Mysliwiec PA, Choi JR, Schindler WR. Location of adenomas missed by optical colonoscopy. Ann Intern Med. 2004;141:352-359.

12. East JE, Saunders BP, Burling D, et al. Surface visualization at CT colonography simulated colonoscopy: effect of varying field of view and retrograde view. Am J Gastroenterol. 2007;102:2529-2535.

13. Westwood DA, Alexakis N, Connor SJ. Transparent cap-assisted colonoscopy versus standard adult colonoscopy: a systematic review and meta-analysis. Dis Colon Rectum. 2012;55:218-225.

14. Bretagne JF, Manfredi S, Piette C, et al. Yield of high-grade dysplasia based on polyp size detected at colonoscopy: a series of 2295 examinations following a positive fecal occult blood test in a population-based study. Dis Colon Rectum. 2010;53:339-345.

15. Gschwantler M, Kriwanek S, Langner E, et al. High-grade dysplasia and invasive carcinoma in colorectal adenomas: a multivariate analysis of the impact of adenoma and patient characteristics. Eur J Gastroenterol Hepatol. 2002;14:183-188.

16. Horiuchi A, Nakayama Y. Improved colorectal adenoma detection with a transparent retractable extension device. Am J Gastroenterol. 2008; 103:341-345.

17. Frieling T, Neuhaus F, Heise J, et al. Cap-assisted colonoscopy (CAC) significantly extends visualization in the right colon. $Z$ Gastroenterol. 2012;50:279-284.

18. He Q, Li JD, An SL, et al. Cap-assisted colonoscopy versus conventional colonoscopy: systematic review and meta-analysis. Int J Colorectal Dis. 2012 (Epub ahead of print). doi:10.1007/s 00384-012-1466-y.

19. Lee YT, Lai LH, Hui AJ, et al. Efficacy of cap-assisted colonoscopy in comparison with regular colonoscopy: a randomized controlled trial. Am J Gastroenterol. 2009;104:41-46.

20. Kim HH, Park SJ, Park MI, Moon W, Kim SE. Transparent-capfitted colonoscopy shows higher performance with cecal intubation time in difficult cases. World J Gastroenterol. 2012;18:1 953-1958.

21. Hsieh YH, Tseng KC, Lin HJ. Limited low-air insufflation is optimal for colonoscopy. Dig Dis Sci. 2010;55:2035-2042.

22. Horiuchi A, Nakayama Y, Kajiyama $M$ et al. Benefits and limitations of cap-fitted colonoscopy in screening colonoscopy. Dig Dis Sci. 2012 (Epub ahead of print). doi: 10.1007/s10620-012-2403-1.

23. Leufkens AM, DeMarco DC, Rastogi A, et al. Effect of a retrograde-viewing device on adenoma detection rate during colonoscopy: the TERRACE study. Gastrointest Endosc. 2011;73:480-489.

24. Harada Y, Hirasawa D, Fujita N, et al. Impact of a transparent hood on the performance of total colonoscopy: a randomized controlled trial. Gastrointest Endosc. 2009;69:637-644.

25. Rastogi A, Bansal A, Rao DS, et al. Higher adenoma detection rates with cap-assisted colonoscopy: a randomised controlled trial. Gut. 2012;61:402-408.

26. Shida T, Katsuura Y, Teramoto O, et al. Transparent hood attached to the colonoscope: does it really work for all types of colonoscopes? Surg Endosc. 2008;22:2654-2658.

27. Tee HP, Corte $\mathrm{C}, \mathrm{Al}-\mathrm{Ghamdi} \mathrm{H}$, et al. Prospective randomized controlled trial evaluating cap-assisted colonoscopy vs standard colonoscopy. World J Gastroenterol. 2010;16:3905-3910.

28. de Wijkerslooth TR, Stoop EM, Bossuyt PM, et al. Adenoma detection with cap-assisted colonoscopy versus regular colonoscopy: a randomised controlled trial. Gut. 2012;61:1426-1434. 
29. Dai J, Feng N, Lu H, et al. Transparent cap improves patients' tolerance of colonoscopy and shortens examination time by inexperienced endoscopists. J Dig Dis. 2010;11:364-368.
30. Choi DH, Shin HK, Lee YC, et al. Cap-assisted colonoscopy can improve the quality of colonoscopy. J Korean Soc Coloproctol. 2010;26:116-122. 